\title{
Iatrogenic phenytoin toxicity: a case report of medication error
}

\author{
Shreya R. Patel ${ }^{1}$, Kamlesh P. Patel ${ }^{1}$, Supriya D. Malhotra ${ }^{1 *}$, Pankaj R. Patel ${ }^{2}$
}

${ }^{1}$ Department of Pharmacology,

${ }^{2}$ Department of Orthopedics, Smt. NHLMMC, VSGH, Ahmedabad, Gujarat, India

Received: 05 June 2017

Accepted: 27 June 2017

\section{*Correspondence to:}

Dr. Supriya D. Malhotra, Email: supriyadmalhotra@ gmail.com

Copyright: (C) the author(s), publisher and licensee Medip Academy. This is an openaccess article distributed under the terms of the Creative Commons Attribution NonCommercial License, which permits unrestricted noncommercial use, distribution, and reproduction in any medium, provided the original work is properly cited.

\begin{abstract}
Medication errors may produce severe toxicity resulting in hospitalization. This can be compounded if the physician obtains the wrong concentration from a reference manual and a pharmacy miscalculates the conversion. We present a case report of phenytoin toxicity related to overdose in 19 year girl which is related to prescribing error and dose related error. A 19 years old girl came to emergency department with convulsions, gum hypertrophy and ataxia. Patient had history of convulsion before 2 months at that time she was given Tab. Phenytoin (100mg) (Eptoin) 2 times a day prescribed for generalized tonic clonic seizures (GTCS). Then before seven days she presented with convulsion so physician increased the dose of drug from 2 times a day to 3 times a day. Then patient developed gum hyperplasia and ataxia after 7 days and she presented with convulsion. Serum Phenytoin level was $>40 \mathrm{mcg} / \mathrm{ml}$. Phenytoin was withdrawn. Then patient then recovered eventually. Medication errors may produce severe toxicity resulting in hospitalization. It also increases morbidity and mortality. A prescribing fault is a failure in the prescribing process. It leads to, or has the potential to lead to, harm to the patient. Phenytoin metabolism is dose dependent. So very small increments in dosage may result in adverse effects. In our case sudden increase in the dose by $100 \mathrm{mg}$ led to blood level double than therapeutic blood level. So, medication error occurred at the prescription level and because of that patient developed toxicity and she needed to hospitalization. In this case instead of suddenly increasing the dose of phenytoin one should change the drug or add another drug to prevent toxicity or side effect.
\end{abstract}

Keywords: Acute over dosage, Medication error, Phenytoin, Saturation kinetics

\section{INTRODUCTION}

Medication errors may produce severe toxicity resulting in hospitalization. This can be compounded if the physician obtains the wrong concentration from a reference manual and a pharmacy miscalculates the conversion. ${ }^{1}$ Medication errors can occur anywhere along the route, from the clinician who prescribes the medication to the healthcare professional who administers the medication. ${ }^{2}$ There are so many types of medication error. We present a case report of phenytoin toxicity related to overdose in 19 year girl which is related to prescribing error and dose related error. The toxic effect of phenytoin depends on the route of administration, the duration of exposure, and the dosage. ${ }^{3}$

\section{CASE HISTORY}

A 19 years old girl came to emergency department with convulsions, gum hypertrophy and ataxia. Patient had history of convulsion before 2 months at that time she was given Tab. Phenytoin (100mg) (Eptoin) 2 times a day prescribed for generalized tonic clonic seizures (GTCS). Patient was taking treatment regularly. Then before seven days she presented with convulsion so physician increased the dose of drug from 2 times a day to 3 times a day. Then patient developed gum hyperplasia and ataxia after 7 days and she presented with convulsion. So, physician suspected phenytoin toxicity. Serum Phenytoin level was $>40 \mathrm{mcg} / \mathrm{ml}$. Patient's CT scan, and MRI report were normal. This confirmed Phenytoin toxicity. Phenytoin was 
withdrawn and Tab. Levetirecetam (500mg) once a day was given. Then patient then recovered eventually. The case was reported via vigiflow to the National coordinating center for ADR monitoring with reference ID No. is 2017 03224. According to WHO-UMC causality assessment, this ADR is fall under probable.

\section{DISCUSSION}

Medication errors may produce severe toxicity resulting in hospitalization. It also increases morbidity and mortality. Errors can occur at any step from selection of medication to drug administration. Recent investigations have shown that an error occurs once in every 20 orders for medications and the most common reason for errors is a prescription error and incorrect dosing. ${ }^{4}$

A prescribing fault is a failure in the prescribing (decisionmaking) process. It leads to, or has the potential to lead to, harm to the patient. The converse of this, 'balanced prescribing' is the use of a medicine that is appropriate to the patient's condition and, within the limits created by the uncertainty that attends therapeutic decisions, in a dosage regimen that optimizes the balance of benefit to harm. ${ }^{5}$

Phenytoin toxicity depends on the route of administration, the duration of exposure, and the dosage. Phenytoin toxicity happens after Phenytoin level is $>20 \mathrm{mcg} / \mathrm{ml}$ and it may be manifested as a syndrome of cerebellar, vestibular, and ocular effects, notably nystagmus, diplopia, slurred speech, and ataxia.

Acute oral over dosage results primarily in signs referable to the cerebellum and vestibular system. Toxic effect includes CNS effects, increased frequency of seizures, GI symptoms, gingival hyperplasia, and megaloblastic anemia. Gingival hyperplasia occurs in $\sim 20 \%$ of all patients during phenytoin therapy. It is probably the most common manifestation of phenytoin toxicity in children and young adolescents and it is because of overgrowth of tissue appears to involve altered collagen metabolism. ${ }^{3}$ In our case gum hyperplasia and ataxia seen at the level of $40 \mathrm{mcg} / \mathrm{ml}$.

Phenytoin is a weak acid and has erratic GI absorption and after ingestion, phenytoin precipitates in the stomach's acid environment. This characteristic is particularly important in the setting of an intentional overdose. Peak blood levels occur 3-12 hours after single dose ingestion. Absorption can be extended up to 2 weeks, especially in massive overdose. Oral exposures are associated predominantly with CNS symptoms. ${ }^{6}$ As it occurred in our case after 1 week of an overdose.

Phenytoin metabolism is dose dependent and its elimination follows first-order kinetics at the low drug concentrations and saturation kinetics at higher drug concentrations. This change in kinetics reflects the saturation of metabolic pathways. So very small increments in dosage may result in adverse effects. ${ }^{6}$
As phenytoin is a drug with narrow therapeutic index, dose increments should be cautiously done. They should be by $25-30 \mathrm{mg}$ rather than straight away in our case as $100 \mathrm{mg}{ }^{7}$ This points to overzealous prescribing. In our case sudden increase in the dose by $100 \mathrm{mg}$ led to blood level double than therapeutic blood level (Figure 1). This could have been well avoided.

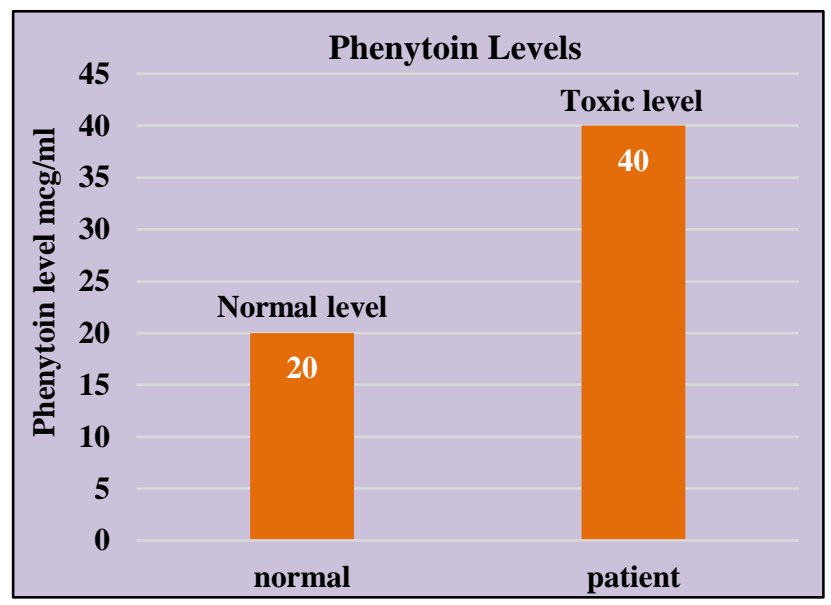

Figure 1: S. Phenytoin level suggesting toxicity.

Another suggestion is that, if phenytoin in usual therapeutic dose is not effective in controlling seizures then rather than increasing the dose of phenytoin to maximum tolerated dose it is better to start with another anticonvulsant concurrently along with phenytoin.

In our case the dose of Phenytoin was 100mg PO TDS in malnourished pediatric girl. So it was very high which led to toxicity. As such phenytoin as monotherapy is not advocated in young females due to cosmetic concerns. Hence according to the authors, drug selection was not proper.

According to weight and age of the patient dose should be $100 \mathrm{mg}$ PO OD initially and then if seizures are not controlled, any other anticonvulsant can be added to the patient's regime.

So medication error occurred at the prescription level and because of that patient developed toxicity and she needed to hospitalization. In this case instead of suddenly increasing the dose of phenytoin one should change the drug or add another drug to prevent toxicity or side effect.

\section{ACKNOWLEDGEMENTS}

Authors would like to thank the professors and residents in the Medicine Department for their help and guidance.

Funding: No funding sources

Conflict of interest: None declared

Ethical approval: Not required 


\section{REFERENCES}

1. Lowry JA, Vandover JC, DeGreeff J, Scalzo AJ. Unusual presentation of iatrogenic phenytoin toxicity in a newborn. J Med Toxicol. 2005 Dec;1(1):26-9.

2. Medication errors in nursing: Common types, causes, and prevention. Available at: https://www.medcomrn.com/index.php/articles/com mon-nursing-medication-errors-types-causesprevention/Accessed on 2/6/2017.

3. Antiepileptics, Sweetman SC, Martindale. The Complete Drug Reference, $36^{\text {th }}$ Edition, USA, Pharmaceutical Press; 2009:495-501.

4. Anonymous. American Academy of Pediatrics: Committee on Drugs and Committee on Hospital Care; 1998;102:428.
5. Jeffrey K. Aronson. Medication errors: definitions and classification, British Journal of Clinical Pharmacology.

6. Miller C. Phenytoin toxicity. Med scape, MD, Updated: Apr 25, 2016.

7. Katzung BG, Trevor AJ. Antiseizures drugs, Katzungs Basic \& Clinical Pharmacology, $13^{\text {th }}$ Edition, New York, NY, Mc Graw Hill; 2015:401.

Cite this article as: Patel SR, Patel KP, Malhotra SD, Patel PR. Iatrogenic phenytoin toxicity: a case report of medication error. Int J Basic Clin Pharmacol 2017;6:2102-4. 